* Livre Docente em Filosofia do Direito pela PUC/SP. Pós Doutor pela Faculdade de Direito da Universidade Clássica de Lisboa e pela Universidade de Coimbra. Doutor, Mestre e Graduado em Direito pela PUC/SP. Graduado em Filosofia pela Universidade de São Paulo - USP. Professor da Faculdade de Direito da PUC/ SP, tanto na graduação, como nos cursos de Mestrado e Doutorado. Autor de inúmeras obras e artigos.

** Doutorando e Mestre em Filosofia do Direito pela PUC/ SP. Professor e coordenador do curso de graduação em Direito da Escola Paulista de Direito (EPD). Professor dos cursos de pós graduação da EPD. Na mesma instituição coordena o grupo de estudos permanentes em Nietzsche. Autor de diversas obras e artigos nos campos da Filosofia e do Direito, destacando-se sua Teoria Ontológica do Direito, publicada pela editora Lumen Juris

\section{INSTÂNCIAS DE ABORDAGEM DO FENÔMENO JURÍDICO: A DOGMÁTICA E A ZETÉTICA}

\author{
Alvaro de Azevedo Gonzaga* \\ Roberto Beijato Junior**
}

Como citar: GONZAGA, Alvaro de Azevedo; BEIJATO JUNIOR, Roberto. INSTÂNCIAS DE ABORDAGEM DO FENÔMENO JURÍDICO: ADOGMÁTICAEAZETÉTICA. Revista do Instituto de Direito Constitucional e Cidadania - IDCC, Londrina, v. 4, n. 1, p 10-23, ago, 2019. ISSN: 2596-0075.

https://doi.org/10.48159/revistadoidcc.v4n1.gonzaga.beijatojr 


\section{INTRODUÇÃO AO CENÁRIO ATUAL DA CIÊNCIA DO DIREITO}

O problema da abordagem do fenômeno jurídico passa, primeiramente, pela própria constituição ontológica do que se pode entender por "Direito". Já dizia Heidegger que o rigor científico não se confunde com a exatidão dos resultados a serem produzidos, mas sim pela melhor forma de abordagem do fenômeno, de acordo com a sua consistência ontológica. ${ }^{1}$

Não sendo neste breve artigo de cunho introdutórios o local mais apropriado para o desenvolvimento da distinção heideggeriana entre o conhecimento ôntico (quanto ao ente) e o conhecimento ontológico (quanto ao ser) ${ }^{2}$, cabe aqui apenas mencionarmos que para concluirmos acerca da instância correta para abordagem do fenômeno jurídico, primeiro precisamos entender a consistência do próprio fenômeno jurídico.

A necessidade moderna pela sensação de segurança faz com que surja no âmago da subjetividade do homem da atualidade a constante necessidade de "sentir" segurança. O Direito, neste ponto, para produzir tal segurança deve transmitir a seus destinatários a mensagem de que constitui um sistema coerente de ordenação de conduta donde se pode, através de deduções silogísticas e exames de semântica normativa prever, de antemão, os resultados esperados, ou seja, resultados de certo modo exatos.

Tal necessidade faz com que se tenha construído um vasto preconceito, seja no âmbito acadêmico, seja no âmbito geral, sobre tentativas de desvelamento da visão corrente de abordagem do fenômeno jurídico que predomina desde o século XIX.

Quando discutimos a forma apropriada de abordagem do fenômeno jurídico, em essência o objeto da discussão é: no que consiste o próprio Direito? Primeiro se precisa responder a tal questão para a partir daí se permitir a solução metodológica.

Se entendemos referido fenômeno tão somente enquanto composto pelas normas jurídicas produzidas pelo Estado - como o faz o positivismo jurídico, conforme veremos - chegaremos à conclusão de que o método de abordagem do fenômeno não pode ser outro senão o exame de tais normas e, por conseguinte, pelo aferimento de sua definição, sentido e alcance. Assim, neste modelo o papel do jurista se restringiria ao de um observador neutro do Direito. O método, propriamente dito, numa tal abordagem do Direito seria, por certo o método dedutivo silogístico, uma vez que sendo o Direito reduzido a uma mera categoria da lógica formal, sua preocupação será apenas com a validade de seus resultados sob o ponto de vista lógico, sem

1 Conferir: HEIDEGGER, Martin. Introdução à filosofia. São Paulo: Martins Fontes, 2008, p. 46/47.

2 Para o que sugerimos conferir: BEIJATO JUNIOR, Roberto. Teoria Ontológica do Direito. Rio de Janeiro: Lumen Juris, 2018. 
referência ao conteúdo valorativo do resultado produzido ou mesmo das próprias normas jurídicas que compõem o Direito. Trata-se esta de uma via epistemológica que condicionará, portanto, a via metodológica de abordagem do Direito.

Por outra esteira, caso pensemos o Direito não apenas como mero conglomerado de normas jurídicas, mas como um fenômeno muito mais complexo e híbrido, no bojo do qual se encontram não apenas as normas jurídicas, mas também fatores econômicos, ideológicos, sociais, políticos,éticos e axiológicos em geral, então teremos que o modo lógico típico da visão anterior não restará suficiente para compreensão da essência do fenômeno com o qual lidamos e, então necessitaremos de outra via metodológica.

As formas de abordagem do Direito, nesta toada, reportam-se antes de tudo à epistemologia jurídica, ou seja, sobre a teoria do conhecimento aplicada ao fenômeno jurídico. Ao perguntarmo-nos acerca do que é o Direito, a resposta nos trará, por conseguinte, a melhor via de abordagem do fenômeno e, assim, a forma cientificamente rigorosa para tanto, a qual repita-se, não se confunde com a exatidão do conhecimento produzido.

Temos, assim, a partir da clássica visão do Prof. Tércio Sampaio Ferraz Júnior, o qual por sua vez, se reporta aos seus estudos com Viehweg na Alemanha, duas perspectivas sobre o fenômeno jurídico, quais sejam: a dogmática e a zetética. ${ }^{3}$

Cada uma corresponde a uma forma distinta de apreender o Direito, porém não necessariamente isoladas uma da outra. Em nossa visão, uma abordagem completa do Direito depende da interação constante entre as duas instâncias.

Ao tratarmos do enfoque da dogmática jurídica a própria terminologia já nos diz: tratam-se de dogmas atinentes ao direito. Por sua vez, o que são dogmas? Dogmas são aquelas proposições tidas de modo irrefutável enquanto verdadeiras. Tratam-se de verdades incontestáveis de um determinado campo. Por isso ao falarmos em dogmas a primeira coisa que vem a mente são os dogmas religiosos. Por certo ao tratarmos do campo da religião, não se questionam os seus dogmas, simplesmente se os cumprindo de modo inquestionável. O termo "dogma", por sua vez,

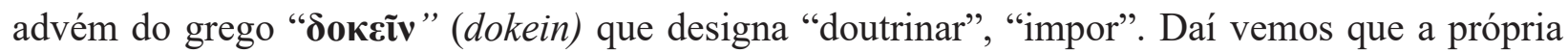
instância dogmática do Direito é a instância composta pelas verdades apriorísticas do direito, ou seja, aquilo que não se põe à prova e se assume como verdadeiro, doutrinariamente.

3 Conferir: FERRAZ JUNIOR, Tércio Sampaio. Introdução ao estudo do direito: técnica, decisão e dominação. 9a ed. São Paulo: Atlas, 2016, p. 18/29 e VIEHWEG, Theodor. Ideologie und Recht. Frankfurt: Vittorio Klostermann, 1969.

Ideologie und rechtdogmatik. 
A dogmática depende de certos pontos de partida que não podem ser objetos de questionamento. Há pressuposições imunes ao questionamento e, a partir de tais pressuposições é que se estrutura o sistema dogmático que regerá as ações dos indivíduos. A principal preocupação e objetivo da dogmática, portanto, é a operacionalização das condutas no campo prático, partindo de certas premissas que se tornam imunes à crítica.

A dogmática do Direito, portanto, é a instância técnica responsável pelo estudo dos conceitos já postos pelo Direito e sua sistematização. Veja-se que se trata de uma instância tecnicista, onde impera o "como fazer" algo em detrimento do questionamento sobre no que consiste este "algo". Assim, perguntas como "o que é o Direito", ou "o que é Justiça" não serão objetos da dogmática jurídica, a qual partirá de uma visão já pronta de Direito ou do Justo e, a partir daí estruturará seus conceitos, suas normas, etc.

Já a zetética, por outro lado, retira este nome do grego Zetein, que designa "indagar", "perquirir". A zetética, portanto, será o campo propriamente dos questionamentos. Ao passo que a dogmática constitui a instância técnica de análise e operacionalização do Direito, ensinando, portanto a "como fazer as coisas", a zetética é a instância efetivamente crítica do estudo jurídico e do Direito enquanto fenômeno, sendo responsável, portanto, por perquirir o significado do Direito e seus institutos.

Apenas para esclarecimentos, quando neste se trabalho se fala em crítica, não se está a mencionar a conotação pejorativa que o termo por vezes recebe. A crítica se caracteriza pela profunda investigação e reflexão sobre a essência das questões enfrentadas para, a partir daí, compreendermos essencialmente o ente com o qual nos deparamos. ${ }^{4}$

No campo da zetética se encontrarão, portanto, os estudos propriamente reflexivos sobre o Direito, questionando-o. Neste campo teremos, por excelência a Filosofia do Direito, além da própria Teoria Geral do Direito e diversas outras matérias como a Sociologia, a Antropologia, a Psicologia, que se debruçarão em suas instâncias sobre o próprio fenômeno jurídico.

A zetética, ao contrário da dogmática, por sua própria natureza filosófica e reflexiva não possui premissas inatacáveis. Assim, o âmbito de cognição da zetética é muito mais amplo que o da dogmática e, deveras, mais complexo.

4 Neste sentido: "Criticar significa indagar das raízes de um problema, daquilo que condiciona, lógica, axiológica ou historicamente, esse mesmo problema. Toda vez que indagamos dos pressupostos ou das razões de legitimidade ou da validez de algo, estamos fazendo sua 'crítica' " (REALE, Miguel. Filosofia do direito. 20a ed. São Paulo: Saraiva, 2002, p. 35). 
Um exemplo que pode ilustrar bem a questão é o da existência de Deus na Filosofia (zetética) e na Teologia (dogmática). A Teologia, enquanto conhecimento de teor dogmático partirá de uma premissa que não se questiona - e não se pode questionar -, ou seja, de um dogma, qual seja, o da existência de Deus. Teologicamente a existência de Deus é uma imanente, um dogma, portanto, a partir do qual as estruturas da Teologia se organizarão. A partir de tal dogma se terá a unidade sistêmica no campo da Teologia, recorrendo-se a uma fundamentação última que justificará todas as imposições que serão feitas em tal estrutura. Assim, por exemplo: no campo teológico não se poderia questionar a regra que veda o adultério, pois em última instância este representa um mandamento de índole divina, fundado na vontade de Deus e que, portanto, torna-se blindado a qualquer instância crítica.

Já no campo da filosofia até mesmo a existência de Deus pode ser posta em dúvida e submetida às instâncias críticas do pensamento em sua plenitude. A filosofia então comporá um saber crítico e reflexivo sobre o arcabouço da dogmática, pondo-a em cheque. Não se ignora, por isso, que a própria filosofia, desde o início da era cristã até a modernidade - mais precisamente até Kant - tenha tido no problema da existência de Deus um de seus principais temas. Por exemplo, em Tomás de Aquino, onde a unidade entre fé e razão pressupunha a própria unidade das verdades racionais e das derivadas da fé, que deviam chegar ao mesmo resultado, a existência de Deus é, em especial, demonstrada a partir da lei das quatro causas desenvolvida no Órganon aristotélico, onde encontrará na causa eficiente a sua principal justificativa. Isto é: tudo provém de algo. Nada pode provir do nada. Portanto o princípio primeiro donde tudo provém somente pode ser Deus. Justificada filosófica e racionalmente a existência de Deus, estes sistemas filosóficos colocavam em posição de conforto os dogmas da teologia correspondente. É somente em Kant que a existência de Deus deixa de ser um problema da razão teórica, uma vez que a metafísica é refutada sob os parâmetros da ciência e passa para o campo da razão prática. No dizer do velho e entediante Kant, ansioso por inserir em seu modelo a justificativa transcendental à sua moral do dever, a existência de Deus é simplesmente um suposto necessário da própria moral. ${ }^{5}$

O âmbito de cognição da zetética é, desse modo, muito mais amplo que o da dogmática. Enquanto a dogmática se restringe ao máximo, até uma pressuposição inatacável e imune à crítica, a zetética e, mais propriamente a filosofia, não possuem limites, colocando sob os olhares críticos mesmo as bases mais fundamentais de um determinado saber.

Ao confrontarmos a dogmática e a zetética temos, portanto, duas formas de organização da razão: uma primeira, típica da dogmática, é a razão reprodutora, isto é, o tipo de raciocínio que apreende uma vasta gama de conceitos e verdades apriorísticas - dogmas - e limita-se a reproduzi-los de forma fiel. Esta forma é apenas um tipo de razão inferior. Isto é, uma

\footnotetext{
5 Cf: Kant, Immanuel. Crítica da razão prática. $3^{\mathrm{a}}$ ed. São Paulo: Ícone, 2007.
} 
razão que não cria, mas apenas reproduz tecnicamente. Uma segunda forma, típica da zetética, é o raciocínio reflexivo, ou seja, aquele no qual o sujeito cognoscente efetivamente debruça-se sobre o objeto e o examina a partir de olhares críticos, colocando neste exame a sua individualidade. A dogmática proporcionará o raciocínio típico do técnico, enquanto a zetética o raciocínio típico do filósofo.

\section{UMA NECESSÁRIA INTERAÇÃO}

Neste ponto podemos nos perguntar: mas e qual o raciocínio apropriado para estudo do fenômeno jurídico, o dogmático ou o zetético?

Se reduzirmos o estudo do Direito à dogmática, temos que o seu estudo será extremamente tecnicista, mas escasso em elementos críticos. Formaremos assim uma legião de tecnocratas e burocratas do Direito, que nada vêem além de simples fórmulas lógicas, reduzindo seu parco horizonte ao âmbito daquilo que lhes é posto.

Por outro lado, se ignorarmos completamente a dogmática em prol de uma abordagem puramente zetética do Direito, sem a mínima objetividade, incorreremos em uma fantasia de Justiça que também ignorará os reais fatores de Poder, política, economia, etc., que influirão sobre a solução a ser dada a diversos problemas jurídicos enfrentados hodiernamente. Por vezes, é de se mencionar, a resposta aparentemente dada pelo sistema jurídico obedece mais aos programas dos sistemas econômico e político do que propriamente os do sistema jurídico. A constatação destes fatos somente pode ser feita a partir de uma análise reflexiva, de um exercício de razão superior e crítica sobre os fundamentos de uma determinada resposta.

Uma abordagem coerente do Direito não pode se dirigir aos extremos, nem chegando a um tecnicismo vazio e medíocre, nem a uma abstração tamanha que perca toda sua operacionalidade prática.

Não podemos esquecer que o Direito é, antes de tudo, um instrumento de ordenação da conduta dos homens, do funcionamento do Estado e da vida em sociedade.

O que se defende, portanto, é que haja uma interação entre as instâncias dogmáticas e técnicas do Direito com a crítica própria da filosofia. Isto é, ao se abordar um problema jurídico, não basta ao estudioso uma mera resposta técnica, cabendo submeter o saber dogmático à crítica, desvelando-o em sua essência e, assim, identificando não apenas a significação da norma jurídica 
analisada, mas também os demais fatores de poder que estão por trás da produção da norma e da própria decisão.

A dogmática do Direito é uma instância indispensável para que o Direito cumpra sua função. Ela fornecerá os alicerces de operacionalização e solução dos problemas concretos à luz de critérios já postos. No entanto, a solução em questão deve ir além da mera forma, atingindo o ser do problema, tarefa que exige do jurista muito mais do que o mero domínio técnico dos conceitos jurídicos, mas o pleno exercício da razão reflexiva.

Esta é a diferença entre o mero operador do direito e o verdadeiro jurista. Um operador é alguém que opera algo, tal como se opera uma máquina. Trata-se do operário do direito. A figura do operador é absolutamente substituível, isto é, faltando um, troca-se por outro, que reproduzirá os mesmos conceitos de igual modo, tal como um operário manuseará do mesmo modo a mesma máquina. O jurista, ao contrário, é aquela que não apenas domina o saber dogmático, mas o submete a crítica, pondo nele a subjetividade de suas reflexões. O jurista sim é insubstituível. Por envolver suas reflexões pessoais, sua intuição, a filosofia é de cunho personalíssimo. O estudante que ingressa nos cursos de Direito Brasil afora deve ter em mente a necessidade de criticar todo o saber que lhe é direcionado, tarefa muito mais árdua do que a mera assimilação e reprodução de referido saber. Tarefa, no entanto, que permite o desenvolvimento pessoal do jurista, a mais profícua assimilação do fenômeno jurídico e, por fim, permitirá que sua função seja semeadora de alguma mudança social.

A sociedade atual, mormente no Brasil, vive momentos de instabilidade. Vejamos por exemplo uma caso recente: em 31 de agosto de 2016 a ex Presidente da República Dilma Rousseff foi condenada por crime de responsabilidade, sofrendo o impeachment. Nestes casos, a Constituição Federal brasileira é bastante clara, no parágrafo único de seu art. 52, que sendo o Presidente da República condenado pelo Senado Federal por crime de responsabilidade, sofrerá cumulativamente as penas de perda do cargo exercido além de ficar inabilitado para o exercício de qualquer função pública pelo período de 08 anos, sem prejuízo da aplicação de outras sanções judiciais cabíveis a serem aplicadas, por sua vez, não pelo Senado mas pelo Poder Judiciário.

O que temos, indiscutivelmente, do ponto de vista constitucional é que a margem interpretativa do dispositivo em questão é bastante estreita. Trata-se de uma regra rígida que dispõe que nestes casos o Presidente sofrerá as duas penas, a serem aplicadas de modo consequente à condenação proferida pelo Senado Federal.

No caso brasileiro, no entanto, vimos de modo surpreendente o Senado 
simplesmente "fatiar" a votação quanto a condenação da ex Presidente. Assim, a mesma fora condenada à perda do cargo que exercia pelo voto favorável de 61 Senadores, porém, apenas 42 senadores votaram pela inabilitação de função pública por 8 anos. Tal situação conduziu ao seguinte resultado: a ex Presidente condenada por crime de responsabilidade perdeu o seu cargo, porém mesmo após a condenação permanece apta ao exercício de funções públicas. Não fosse seu segundo mandato poderia, nas próximas eleições se candidatar novamente para o mesmo cargo. Pode, no entanto, exercer desde já outras funções públicas, ainda que de cunho eletivo.

Tal situação não é permitida pela Constituição brasileira, bastando mera leitura do parágrafo único do art. 52 para chegarmos a tal conclusão. No entanto, questiona-se: como então chegou-se a tal resultado? Ora, se analisarmos a questão apenas do ponto de vista da dogmática, não teremos como fornecer uma resposta palpável. Fato é que se trata de uma decisão manifestamente inconstitucional mas sobre a qual simplesmente se fizera "vistas grossas" em face da situação calamitosa de instabilidade política que vem sendo vivenciada no Brasil.

Ao analisarmos o problema do ponto de vista zetético veremos, no entanto, como as formas dogmáticas, quando avaliadas isoladamente, são facilmente manipuláveis. Assim, por trás da decisão que ora comentamos há, indiscutivelmente, um fator político. A razão pela qual decidiu-se "fatiar" - de modo absolutamente inconstitucional - a aplicação das penas é política e, não técnica e jurídica. Ocorre que a razão política não se encontra explícita na decisão, mas sim ocultada pelas formas jurídicas típicas da dogmática. Assim, em vez de se transparecer a motivação para a decisão - o que seria pressuposto de toda conclusão jurídica - se a oculta sob a feição de uma manipulação hermenêutica do dispositivo positivado, no caso em questão o parágrafo único do art. 52 da Constituição Federal.

Para nos valermos do termo introduzido pro Luhmann, é o exame zetético da situação que proporcionará a constatação de que o Direito, mormente no Brasil, vem operando constantemente de um modo sistemicamente corrupto. Corrupção sistêmica no sentido luhmanniano ocorre quando um determinado sistema passa a ser operado não por seus próprios programas e códigos, mas sim pelos de outro sistema que habita o mesmo ambiente. Os programas da política permeiam o Direito e nele exercem maior preponderância do que os próprios programas normativamente inscritos no sistema jurídico. A hermenêutica desviada serve apenas à outorgar aparência de que a decisão, isto é, o resultado de uma questão jurídica obedece ao código jurídico, ocultando a corrupção sistêmica que lhe fora subjacente. Uma dogmática pura é incapaz de formular estas constatações, carecendo de cognoscibilidade complexa o suficiente para este fenômeno.

A análise jurídica, portanto, principalmente do ponto de vista do rigor científico, não se contenta com o estudo estritamente dogmático. Isto porque o mesmo facilmente oculta as 
variáveis que conduzem ao resultado, de modo que a decisão torna-se muito mais um fator de escolha e de poder do que uma consequência imanente da ordem jurídica.

É necessário nos armarmos da reflexão para que tenhamos conhecimento dos reais fatores que conduzem à solução de um determinado conflito. A Lei é apenas um dos fatores que conduzem a tal conclusão, mas nem de longe o único. ${ }^{6}$

Pensemos em outro exemplo para ilustrar o ponto em estudo. Vejamos o direito ao voto. A dogmática jurídica constitucional nos dirá que todo Poder emana do povo. O voto nada mais é, portanto, que um importantíssimo instrumento por meio do qual se faz valer a soberania popular, constituindo-se no exercício da cidadania ativa pelo cidadão que a partir de tanto terá crucial participação nos deslindes políticos do país e na gestão da coisa pública. Trata-se, por certo, de uma referência absolutamente acrítica, típica do tecnicismo dogmático isolado de qualquer referência filosófica.

Podemos pensar, sob outro prisma, o mesmo problema do direito de voto sob o prisma filosófico, onde então poderemos questionar a premissa dogmaticamente imposta relevância do direito de voto; efetivo exercício do poder pelo povo, etc. -. Partindo de uma tal análise passamos a poder criticar o modelo democrático delineado pela Constituição de 1988 a partir, por exemplo, da teoria dos sistemas. ${ }^{7}$

Podemos pensar o Direito sob a perspectiva de um sistema, ou seja, um conjunto de partes coordenadas que forma um todo complexo. No caso do Direito temos, sem dúvidas, um sistema aberto, ou seja, um sistema suscetível de influência de variáveis atinentes ao ambiente no qual está inserido.

Dentre as características fundamentais de todo sistema temos a sua autopreservação e autoreprodução. Isto é, todo sistema visa a sua própria manutenção ad aeternum, não possuindo prazo de validade.

Para destruir um sistema, fazendo-o ruir, a única forma é atingindo o seu núcleo, a sua base vital sem a qual o todo desmorona. Caso, ao contrário, se busque alterar o sistema sem, no entanto, rompê-lo por completo, fazem-se apenas modificações em suas laterais, preservando o núcleo sistêmico. Nesta medida, os sistemas se adaptarão em vista da sua autopreservação a partir da própria heterostase que é característica dos sistemas. Isto é, sofrendo o sistema uma ação

6 Conferir: PUGLIESI, Márcio. Teoria do direito. $2^{\mathrm{a}}$ ed. São Paulo: Saraiva, 2009;

7 Conferir: BERTALANFFY, Ludwig Von. Teoria geral dos sistemas. Petrópolis: Vozes, 1973. 
imprópria, de desgaste sobre si, este tende a manter o equilíbrio, se adaptando, desde que seu núcleo seja preservado. Rompido o núcleo, rui-se o sistema.

Aliando-se a heterostase à própria tendência de autopreservação de todo sistema, pode-se concluir seguramente que para atingir o núcleo sistêmico jamais encontraremos o mecanismo para tanto inserto no próprio sistema, uma vez que isto implicaria em reconhecer que o sistema fornece os meios para sua própria autodestruição, em desacordo com a heterostase típica de todo sistema.

De tal fato ao pensarmos no famoso jargão reproduzido nas épocas de eleição de que deve o cidadão "votar conscientemente, pois essa é sua maior arma", vemos que se trata, na verdade, de uma falácia. O que é o direito de voto senão um instrumento do próprio sistema em vista da sua constante manutenção? Jamais por meio do direito de voto teremos alterações substanciais, portanto, no campo político, digo, alterações suficientes para atingir o núcleo do sistema constitucional brasileiro, ao ponto de fazê-lo ruir e, consequentemente, construir-se outro sistema. O que teremos, por meio do direito de voto são alterações sobre as beiradas do sistema, a partir das quais este se adaptará e permanecerá. Por meio do direito de voto podemos alternar o exercício - e os benefícios - do poder, ora para o partido "A" e seus coligados,ora para o partido "B" e os seus, porém para o povo, suposto detentor do poder, o núcleo duro permanecerá.

O mesmo se diga das famosas passeatas Brasil a fora tão comuns atualmente, onde milhares de pessoas se reúnem para gritar palavras de ordem e assoprar suas cornetas. Gastam sua energia e voltam para casa anestesiados, com a sensação de dever cumprido. Porém, altera-se o sistema na essência por meio de tais condutas? Obviamente que não. Trata-se apenas do direito de reunião para fins pacíficos e sem armas, previsto pelo mesmo sistema constitucional em questão. Assim, tem-se a sensação de movimento quando se está na inércia e tudo continua como está.

Ao pensarmos, então, no direito de voto, vemos que uma análise estritamente dogmática e acrítica o colocará no pedestal dentre os mais importantes direitos fundamentais, cláusula pétrea constitucional. Ao aliarmos a zetética, ao menos colocaremos em dúvida os atributos referenciados pela dogmática, permitindo a sua crítica. ${ }^{8}$

Daí temos que a dogmática jurídica não pode ser estudada de modo isolado, mas sim de modo absolutamente interado com a filosofia e as demais matérias de índole zetética.

8 Um aprofundamento da crítica a esta questão é feita no seguinte artigo: BEIJATO JUNIOR, Roberto. A falência da democracia brasileira. Revista filosofia, ciência e vida. n 131. São Paulo: Editora Escala, 2017, p. 24/27. 
Na Teologia se aceita a redução dogmática do problema da existência de Deus e sua imunização a fim de organizar-se as bases da religião. Reduzindo-se o Direito à abordagem dogmática temos, então, que a "ciência" do Direito não passaria de uma Teologia ou de uma religião do Estado. ${ }^{9}$ O status de cientificidade do Direito pressupõe, portanto, a interação entre dogmática e zetética, sob pena de sequer termos um campo do conhecimento tido efetivamente por científico no Direito.

\section{A ZETÉTICA APLICADA AO SUPREMO TRIBUNAL FEDERAL}

No item anterior mencionamos a endêmica corrupção sistêmica sofrida pelo sistema jurídico pelos demais sistemas que habitam o ambiente da sociedade. Indubitavelmente os sistemas de maior repercussão sobre o sistema jurídico são o econômico e o político. Não raro, uma decisão aparentemente jurídica obedece, a bem da verdade, não aos programas e códigos do sistema jurídico, mas ao contrário, aos da política e da economia, servindo o Direito apenas como um instrumento de ocultação das razões subjacentes a uma dada decisão no melhor interesse dos sistemas em questão.

Como dito, uma análise meramente dogmática não será apta a constatar estes fatos, buscando sempre razões intrínsecas ao Direito para tentar explicar certos fenômenos do ponto de vista técnico e, limitando-se, ao máximo, em criticar o resultado a partir da perspectiva técnica empregada. O que se ignora, na perspectiva dogmática, é justamente os fatores de maior relevância no meio social. A técnica jurídica é de menor valia, sendo facilmente manipulável ao sabor do resultado almejado. O que efetivamente precisa ser avaliado são as razões por trás disso e, aí sim, impor o Direito como um forma de limitação a certos programas da política e da economia.

Podemos mencionar um breve histórico de decisões proferidas no âmbito do Supremo Tribunal Federal que evidenciam esta corrupção sistêmica endêmica que assola a jurisprudência pátria.

O Supremo Tribunal Federal, como a própria Constituição Federal declara em seu art. 102 é o guardião da Constituição. Isto é, cabe-lhe, em última instância, proteger a Constituição e seus preceitos. Há certo tempo, no entanto, o Supremo Tribunal Federal converteu-se de protetor em proprietário da Constituição. Existe uma grande diferença - que por vezes se mostrará muito tênue - entre o ato de proteger um preceito constitucional e o ato de modificá-lo, emendando-o.

9 O que é bastante evidenciado por Carl Schmitt em sua Teologia Política, na qual uma das bases fundamentais constatadas pelo autor é a construção teológica, porém secularizada do Estado moderno. Para tanto sugerimos a leitura da parte da um da Teologia Política, de 1922, em que se trata, especificamente, os problemas atinentes à soberania. Conferir: SCHMITT, Carl. Teologia política. Trad. Elisete Antoniuk. Belo Horizonte: Del Rey, 2006; 
Básico na teoria do direito constitucional e, no modelo de separação de poderes adotado pela Constituição Federal de 1988 é que ao Poder Judiciário não é atribuído poder constituinte derivado. Isto é, a modificação da Constituição não se pode fazer através de decisões judiciais de seu guardião, mas através do Poder Legislativo Federal que, em virtude da rigidez constitucional, terá um árduo procedimento legislativo para que logre êxito em aprovar emendas constitucionais e, aí sim, alterando legitimamente a ordem constitucional.

Por vezes, se mostrará tênue o limite entre hermenêutica e emenda da constituição. As normas constitucionais estão abertas à exegese do seu guardião, no caso, o Supremo Tribunal Federal. Isto não se discute e, é bastante essencial para a manutenção de uma ordem constitucional hígida. Interpretação, contudo, se faz a partir do texto e dentro dos limites de possibilidades conferidas pelo próprio texto. Teremos textos normativos dotados de maior ou menor grau de abstração e generalidade, permitindo, assim, usando o termo de Miguel Reale, uma maior ou menor capacidade de elasticidade da norma. Dentro da elasticidade normativa, será permitida a interpretação pelo poder judiciário. Rompida a elasticidade, contudo, não estamos diante de interpretação, mas sim de modificação da norma.

Um exemplo simples: a Constituição em seu art. $1^{\circ}$, inciso III, dispõe que um dos fundamentos da República é a dignidade da pessoa humana. É claro que esta norma possui um grau de abstração e generalidade elevadíssimo. Assim, permitirá uma criação hermenêutica bastante elevada a diversos casos a serem enfrentados. Por outro lado, a Constituição também em seu art. 226 dispõe expressamente que se reconhece como entidade familiar a união entre homem e mulher. Daí pergunta-se: qual é o grau de elasticidade desta norma? Certamente, bastante restrito, vez que dificilmente se pode compreender nos termos "homem e mulher" algo diverso de "homem e mulher".

No entanto, o Supremo, no julgamento da ADPF $n^{\circ} 132$ reconheceu as uniões homoafetivas como integrantes do conceito de família disposto pelo art. 226 da Constituição. Parece bastante óbvio, do ponto de vista zetético, que esta decisão rompe abertamente com a elasticidade hermenêutica permitida pelo art. 226 quando define família como união entre "homem e mulher". Não se tratou, portanto, de uma interpretação, mas sim de uma modificação da Constituição. A modificação levada a intento pelo Supremo se configura como autêntico exercício de poder constituinte derivado, poder este que, como dissemos, o Supremo não possui.

Por outro lado, certamente a vasta maioria de nós dirá que ideológica e politicamente concorda que o Estado deva, de fato, reconhecer as uniões homoafetivas como família e, por isso muitos aplaudiram esta decisão. De fato, do ponto de vista da política a decisão se mostra acertada. No entanto, o valor da Constituição e do próprio Direito demanda que, por vezes, 
deixemos de lado nossas convicções pessoais, nossas preleções políticas, em prol do cumprimento da ordem jurídica. Esta não pode ceder às preleções particulares, sob pena de vez após vez o Direito restar cada vez mais fragilizado, o que se vem observando no momento em que vivemos.

O Supremo Tribunal Federal não possui o poder de emendar a constituição. No entanto, assim procedeu na ADPF 132. O fez em uma questão que, do ponto de vista ideológico agradou a grande maioria e, por isso se protegeu das críticas. Trata-se de uma tática já descrita por Maquiavel. Quando se arroga de um poder que não possui, é necessário, primeiro, fazer com que o poder não seja questionado. A melhor medida para tanto é agradar. Firmado o precedente de poder, abrem-se as portas para que, em outros casos, se exerça, novamente, o poder e, destas vezes, para questões que não necessariamente agradem essa maioria.

Na ADPF 132 firmou-se um precedente de poder por meio do qual o Supremo se arrogou de uma atribuição que a Constituição não lhe outorga. Valendo-se de tal poder já consolidado, por exemplo, nos Recursos Extraordinários 602.043 e 612.875 o STF firmou o entendimento de que o teto remuneratório do funcionalismo público deve ser aplicado, em caso de cargos cumulados, individualmente para cada cargo. Isto é, se um funcionário público exerce funções cumulativas - a exemplo de um Ministro do STF que seja simultaneamente Ministro do TSE - o teto será aplicado para cada um dos cargos individualmente, podendo-se chegar ao resultado de o teto ser recebido por duas vezes, ou seja, uma vez em cada cargo. O art. 37, XI da Constituição Federal é claríssimo ao determinar que nenhum funcionário público receberá mais do que o salário de um Ministro do STF, independentemente da nomenclatura empregada à verba, seja ela de natureza salarial ou indenizatória e, seja o emprego ou função única ou cumulativa. $\mathrm{Na}$ hipótese ora em tela, certamente o resultado não agradará ideológica e politicamente a maioria das pessoas, que verão no caso uma imoralidade descarada. Todavia, o precedente de poder já havia sido firmado anteriormente e, poder que vale para aquilo que nos agrada, vale também para aquilo que nos desagrada.

Inúmeros serão os casos em que, a partir de uma análise zetética, constataremos esse tipo de atuação por parte do Supremo. O mais recente, sem dúvida, é a criminalização da "homofobia" que se encontra pendente de julgamento, porém contando já com quatro votos favoráveis.

A criação de um tipo penal via decisão judicial constitui uma autêntica aberração jurídica. Mais: é preceito básico do direito penal brasileiro o de que não cabe, na seara penal material o emprego de analogia. Tal prática violaria o princípio da estrita legalidade. 
Não obstante, todos os ministros que votaram até o presente momento equiparam o ato de "homofobia" ao de racismo, aplicando, portanto, a lei que define o crime de racismo. Se trata, à evidência, de um claro emprego de analogia, obviamente vedado em direito penal. Mais uma vez: talvez a criminalização em questão atenda aos anseios políticos e ideológicos de muitos. Porém, teremos aí a fixação de mais um precedente de poder: o de criar tipos penais. Fixado este entendimento, sem qualquer contra-movimento, vejamos para o que será usado este precedente no futuro.

Para tanto, prossigamos no emprego da zetética, da crítica reflexiva sobre a atuação do guardião da Constituição, a fim de que este retorne a ser um protetor da Constituição e não, justamente um de seus principais violadores.

\section{REFERÊNCIAS BIBLIOGRÁFICAS}

BEIJATO JUNIOR, Roberto. Teoria Ontológica do Direito. Rio de Janeiro: Lumen Juris, 2018;

BERTALANFFY, Ludwig Von. Teoria geral dos sistemas. Petrópolis: Vozes, 1973;

FERRAZ JUNIOR, Tércio Sampaio. Introdução ao estudo do direito: técnica, decisão e dominação. 9a ed. São Paulo: Atlas, 2016;

HEIDEGGER, Martin. Introdução à filosofia. São Paulo: Martins Fontes, 2008;

Kant, Immanuel. Crítica da razão prática. $3^{\text {a }}$ ed. São Paulo: Ícone, 2007;

PUGLIESI, Márcio. Teoria do direito. 2a ed. São Paulo: Saraiva, 2009;

REALE, Miguel. Filosofia do direito. $20^{\text {a }}$ ed. São Paulo: Saraiva, 2002;

VIEHWEG, Theodor. Ideologie und Recht. Frankfurt: Vittorio Klostermann, 1969. Ideologie und rechtdogmatik;

VIEHWEG, Theodor. Tópica e jurisprudência: uma contribuição à investigação dos fundamentos jurídico-científicos. Trad. Kelly Susane Alflen da Silva. $5^{\text {a }}$ ed. Porto Alegre: Sergio Antonio Fabris Editor, 2008.

Recebido em: 23/04/2019.

Aprovado em: 09/05/2019. 